\author{
URSZULA M. ŻEGLEŃ \\ Nicolaus Copernicus University \\ Department of Cognitive Science and Epistemology \\ Institute of Philosophy \\ Toruń, Poland
}

\title{
BETWEEN CONTINGENCY AND NECESSITY OF HUMAN ACTION. ARE WE FREE IN OUR CHOICES?
}

\begin{abstract}
The point of departure of this paper is the characterization of human action as contingent or necessary (obligatory). The key question concerns the place for choice in the human action, i.e. are we free in our choices? Thus, the aim of this paper is to search for the answer to the question concerning human freedom and free will. In searching for the answer to this controversial question, consideration is focused on the cognitive structure of human beings. The research refers to Roman Ingarden's conception of the human being as a relatively isolated system of a higher order, contained in a compound hierarchical structure. In this way, the argumentation for the place of free will is supported by the structure of the human being, and joins both the ontological and the epistemic aspects. In consequence, methodologically they are treated as a primary to inquiries into the theory of action on one side, and into the biological approach of cognitive science on the other.
\end{abstract}

Keywords. Human actions, contingency and necessity of actions, concept of chance, human freedom, free will.

\section{Introduction}

The inspiration to this paper, which has been prepared for the jubilee philosophy conference of the $70^{\text {th }}$ anniversary of Łódź University, was Janina Kotarbińska's approach to human events and actions, based on her analysis of the concept of chance (KOTARBIŃSKA [(1934) 1990]). The aim of the paper is not, however, a conceptual analysis, although basic concepts used to characterize human action will be defined. As announced in the title, I assume that human action is extended between contingency (associated with possibility) and necessity (associated with obligation).But what does it mean? To answer this question, I will provide the characterization of these modalities in reference to human action. Generally speaking, by human action I mean such an action which is undertaken by someone consciously with an intention to achieve something and performed at a time (usually in a period of time) at which a given agent has awareness of what he or she is doing as an acting subject. However, the above should not be understood in a strong sense, because a great number of actions, or 
partial actions carried out over a period of time, can be performed in some sense "automatically", e.g. driving a car on a motorway. But such an action as driving a car on a motorway occurs in a wider context and it is a part of someone's action undertaken in order to achieve a goal (to travel for vacation, to transact business, etc.). ${ }^{1}$ And this kind of action is relevant for my considerations, in which the key question are we free in our choices? concerns human freedom and free will. The answer to this question will be the aim of the paper. In looking for the answer to this controversial question, I intend to argue for the place of free will in the cognitive structure of human beings. Following Roman Ingarden, I will support my argumentation of the thesis according to which a human being is a relatively isolated system of a higher order, consisted in subsystems which build a compound hierarchical structure. In this way, I want to combine both the ontological and the epistemic aspects, and treat them methodologically as a primary to inquiries into a theory of action on the one hand, and to a biological approach in cognitive science, on the other.

\section{Human action as extended between contingency and necessity. The place for choice: commitment to the problem of free will}

The title of my paper points out my interest in the human action as extended between contingency and necessity. In which sense of "contingency" and "necessity"? What does the concept of "contingent action" mean? The earlier methodological question is: what is needed to characterize human action? As is known, human action can be characterized at different levels (which can be connected in different ways, although their connection is a serious problem of metaphilosophical controversies):

(1) physical - in respect to its cause, which can be external (outside the agent) or inner (in his organism or mind) (see different approaches in: DAVIDSON [1963/1980], GOLDMAN [1970], ACQUILAR \& BUCKAREFF [2010], PIETROSKI [2000]),

(2) logical - in respect to its reason, which, treated as a normative statement, justifies agent's actions (e.g. FINDLAY [2010]) $)^{2}$ or (2a) formal-logical - in respect to a formal analysis given in different systems of deontic logic (or wider - logic of action) (e.g. v. WRIGHT [1963], TRYPUZ [2008], CZELAKOWSKI [2015]),

\footnotetext{
${ }^{1}$ In analysis, the goal of action should be distinguished from the goal of its agent. The differences connected with the approaches to the goal are the subject of controversies among philosophers who deal with the theory of action.

${ }^{2}$ The issue of reason, however, is much wider and encompasses various approaches to reason. See an overview by ALVAREZ [2010], among others.
} 
(3) epistemic - respect respect to the agent's intentions, beliefs, decisions, knowledge (different approaches given by ANSCOMBE [1963], GRICE (1971), DAVIDSON [1980], VELLEMAN [1989])

(4) pragmatic - in respect to its intended goal and its effect (e.g. KOTARBIŃSKI [1975]),

(5) psychological - in respect to the agent's motivations, preferences, feelings, emotions (e.g. Zhu \& Thagard [2002]),

(6) social - in respect to interactions with other agents, communities, institutions (e.g. Gilbert [2000]),

(7) axiological - in respect to the system of values and norms(which is especially seen in classical approaches of phenomenologists SCHELER [1973], [1992], HILDREBRAND [1916], or later approaches associated with Thomism, as in WOJTYŁA (1969) [1979]). ${ }^{3}$

Human action is included in the wide network of various (physical) events. In the standard approach, every event has its cause (as its efficient power) and happens under certain conditions which make it possible to realize.

Events are distinguished in respect of their character (although they can be connected in different ways). Let me distinguish here:

(1) physical events in their nature, i.e. events of nature (such as storms, tsunamis, earthquakes etc.)

(2) events in the techno-world (for example, a car or plane accident, the demolishing of a building, a nuclear explosion),

(3) intended events being indirect results of someone's actions (for instance, preparing this text for publication).

Further, in the human action one can stress its globality (the example of the Second World War) or locality, as in the case of the action of a team or of an individual agent. It is trivial to say that the dynamicity of human life in society, history and culture (science, art, religion) is manifested in human actions. Human action can be considered in relation to time, as a certain event which happens at a moment of time $t_{i}$ (although it need not to be exactly "any moment", for example, in descriptions of some cultural events such as "the Chopin competition in Warsaw in 2015") or as a process extended in the period of time (for example, training, education, medical treatment, etc).

When I talk about action I distinguish it from behaviour as a result of biological processes of the body. I am not interested in the behaviour of the human body in everyday actions or actions of other kinds, unless it has a special meaning for a given action, for instance, when raising the hand in an election meeting. Then my focus is not on sensomotor processes, which are its efficient cause, but on

\footnotetext{
${ }^{3}$ I do not mention the ethical level separately, as it is included in the axiological one, but also considerations which are made at other levels take into account ethical issues.
} 
someone's conscious beliefs, which are the reason for undertaking this very decision. Thus, a particular action should be considered in a given situation in its special context. I am not interested in sensomotor processes because they should be identical for the same type of behaviour undertaken in different actions, while reasons can be different even in the same type of action undertaken by two agents or by the same agent, but at different times and situations. Beyond that, in the explanation, which is treated as a kind of compound reasoning, reasons (not causes) are taken into account. This is the essential difference between reasons and causes; reasons are considered at the logical level and concern beliefs given in a form of propositions, while causes are considered at the physical level (both macro- and micro-level) and concern events (or states). This means that a causal relation occurs between events (or states).

Let us come back to the example of election, for the time of Libet's experiment this is a standard example in the polemics on free will ${ }^{4}$. At this point, I want to refer to the subject matter of the paper stressed in its title. Is, for example, a presidential election contingent or necessary? According to the state constitution, it is necessary. But citizens in a democratic country can treat their participation in the election as their privilege and each citizen is free in their choice (both in his or her participation in the election and the choice of the candidate for president), although there are many factors which determine that choice. In the discussion of our choices (independently of their subject), first and foremost I take into account the agent's beliefs which lead him (or her) to undertake a particular decision. I do not take into account someone's spontaneous reaction without any reflection (as it would be in the case of pressing the button without any knowledge concerning the purpose of this kind of behaviour).

Let us establish the sense of contingency and necessity. Strictly speaking, contingency (Lat. contingens) is a metaphysical concept, and as such it is treated as an attribute of being.

(Df 1) "Something is contingent" means that it does not exist in and of itself but has the source of its existence in another being.

In this sense each of us, humans, is a contingent being because no one has given himself his biological existence. In consequence, a contingent being might not exist or might have other attributes. There is rich literature on the analysis of this concept in reference to traditional Aristotelian-Thomistic metaphysics. ${ }^{5}$ Here, I distinguish between the metaphysical notion of "contingent" and the notion of

\footnotetext{
${ }^{4}$ Here I will not refer to this experiment, there is sufficient literature on this issue. In Poland for instance BREMER [2013], pp. 186-224 .

${ }^{5}$ Various definitions of contingency by means of alethic modalities (given by Innocenty Maria Bocheński, Tadeusz Czeżowski, Jan Łukasiewicz, Jaakko J. Hintikka, among others) can be found in my book ŻEGLEŃ [1990].
} 
"accident" (not in any metaphysical sense as a non-necessary attribute of being, but as a physical predicate which is ascribed to a description of physical events or processes). "Something happens accidentally" means "by chance" (but the analytic philosopher is dealing with a very rich analysis, in Poland excellently given by Janina Kotarbińska [(1934) 1990], and recently reconstructed and commented by Dariusz Łukasiewicz [2014]). In classical metaphysics, all real entities (i.e. beings in time) are contingent. They are not eternal, but destructible and mortal (if they are living creatures). The human being is contingent. In one sense, which I assume here, the contingent action is the one that its attribute ("contingency") is derived from the nature of the agent who is the subject of the action and its author. Then, all human actions would be contingent. But I also admit another sense of contingency, when the attribute "contingent" is derived from the nature of the action. This sense of contingency is connected with the sense of accidence in my analysis.

(Df 2) The action is contingent when it has not been intended (and/or is undertaken, at least at the beginning, without any plan), but the situation (under unexpected conditions) gives the agent occasion to act.

For example, an unexpected meeting in Łódź with my old friend. This means that the agent starts to act accidentally (by chance), for instance - to greet her old friend in a special way to manifest her sincere joy, to suggest a meeting in the evening. Thus, this notion of "contingency" covers the notion of "accidence" (although the notion of "accidence" has also many other meanings). Deeper analysis could show that it is contingent (by chance) at the macro-level, in referring to a particular event which is constituted for this action (and it is its cause), but it is not such in referring to other events which, in fact, are in the causal chain of this event and hence, they determine it (this case has been precisely analyzed by Kotarbińska/Łukasiewicz in a quoted publication). For a philosopher, it is the core of controversy which is much deeper than given in reference to our usual everyday actions and events. A deep philosophical question is: do we live in a determined world (in which all events are causally connected in a certain way, and then also events which seem to happen by chance are in fact determined), or is the world not wholly determined (and then there is room for events which happen by chance and are explained within the framework which permits indeterminism)? In the scientific worldview, the world (the universe) is a multi-dimensional and very compound closed system. Rejecting Laplace's traditional determinism, contemporary science shows us a much more complicated picture of the world than the traditional scientific or philosophical one. This picture is not homogenous, even in one domain where the inquired events or processes are explained by different models, and physical events are governed not only by strict (deterministic) laws, but also by statistical and probabilistic ones. From the beginning of the $20^{\text {th }}$ century research at the micro-levels (in quantum physics and molecular biology) has become 
a challenge both for scientists and philosophers. The former, by their theories and discoveries, are committed to philosophical questions in their own disciplines, while the latter do not want to remain neutral towards a scientific worldview and even feel obliged to attend contemporary debates. Especially if in the light of discussed controversy, the possibility of free human choices is negated because of argumentation given on the basis of scientific data about the illusion of free will. If in turn the philosopher admits the worldview in which the world in its complexity is, however, an open system, then his picture of the world is quite different from a scientific one. ${ }^{6}$ Let us stay by this assumption with the scientific worldview in which the world is a complex close system. Where is there any room for human action in such a worldview? This question will carry further those considerations which belong to philosophy.

Let us ask now about obligatory actions. There are many cases which can be given as examples for required necessary actions, such as medical help, military defence, religious practices for believers, economic actions, etc. They are obligatory in a different sense, some in a moral and professional one, others in political or economic responsibility. But even if the agent is obliged to undertake an action (and to act in a certain way) he may not fulfil his obligations in spite of serious (sometimes dramatic) results and consequences of that for himself and others.

Thus, it is not the strong (logical) sense of necessity as the attribute of something for which it is impossible not to be (the same as it is impossible to be in another way). But I suppose that you can also give examples of many situations of determined action in which the agent (being constrained) has no choice. Then I take into account not only the external determination but the "inner attitude" of the active subject (as in the extreme cases of people in concentration camps or offers of a martyr's death). Nevertheless, to be fully constrained externally, man can retain freedom in his way of thinking. But it is a topic for another consideration where the problem of free will is considered more holistically within a wider conception of human freedom like the self-determination of an individual person during the whole of his adult life. I do not develop this

\footnotetext{
${ }^{6}$ Although some contemporary philosophers try to make the best of both approaches, mainly in cosmology (such as Michał Heller in Poland) or the philosophy of God (like Alvin Plantinga, for instance). In the recent Polish literature this topic is discussed by Łukasiewicz [2014].

${ }^{7}$ A philosopher does have, however, the right to ask whether the scientific worldview is sufficient for the domain of the universe as well as asking does a concept of scientific rationality exhaust the category of rationality. In my own approach, I distinguish strictly scientific questions from philosophical ones, although in science there are also many philosophical questions. Nevertheless, some questions can be justified in philosophy, not in science, for instance, questions concerning the existence of God, the ultimate sense of the existence of man (or the world). It does not mean that philosophy is able to provide answers to them, nevertheless, it is qualified to ask them to look for their answers.
} 
approach because I intend to deal with the issue of free will more in discussion with some aspects of the scientific worldview.

Let us return to the question concerning the action. What about the action itself? Is it necessary for the human being? The answer to this question concerns a strong (logical) sense of necessity. The human being is naturally a rational and active being. In my view, the argument of neurological deficits of human rationality does not concern human nature, although it points out cases in which particular human beings can have such deficits which break this rationality. It does not, however, concern the metaphysical concept of human nature as rational in spite of the fact that here this concept should adjust with the natural (biological) one. In the biological hierarchy of beings, a human being is rational and, as such, is able to act rationally. A human being, just as a rational being is able to guide their action by different reasons (to estimate them in the light of accepted criteria), is able to make choices (even if these choices are limited and determined by different factors and the agent is not always aware of them). Thus, where should we look for the possibility of choices in human actions? The simple reply "in free will" appears to be one of the most controversial philosophical answers. Let us try to deal with this problem here.

\section{The search for the solution of the problem of free will in the structure of the human being}

As a philosopher, I am looking for a solution which has its ontological ground in the structure of being, which should be complex in such a way that it would be possible for an agent to interact with other beings and which should discover the multiple dimension both for a human being and its action as specific for man.

One can find a promising direction of studies in Roman Ingarden's conception of the human being, inspired by Ludwig von Bertalanffy's theory of system (BERTALANFFY [1957], INGARDEN [1972], p. 136). ${ }^{8}$ According to Ingarden, a human being is just a complicated, compound, multi-dimensional, relatively (partially) open and partially isolated system of higher order. As an open system, it is able to enter into relations with other objects which can also be interpreted as various kinds of similar (in respect to their structure) systems. Openness of a system allows for transition from its causal processes beyond that system. Without such processes, an individual being could not have any attributes which would be externally conditioned or acquired. But the system is not quite open because then it would be a process (not individual). It could not

\footnotetext{
${ }^{8}$ Ingarden was only inspired by Bertallanffy's idea, but in his critical reference to Bertalanffy's conception he developed his own approach. Today such a system approach is developed by Mieczysław Lubański [1997] and Robert Poczobut [2010].
} 
behave in its specificity or stability (in its integration). Thus, it is only relatively, partially open and partially isolated. It is isolated in a certain ontic sense which allows it to behave in its autonomy and distinctiveness. This ontological assumption concerning the structure of the human being as a compound, multidimensional system is in agreement with the biological approach to man as the organism taken together with its processes and subsystems which are causally conditioned by external factors, and produce various effects on their environment. In the hierarchical structure of the human being, all these subsystems are in special types of dependencies, such as:

(i) existential - according to which the destruction of basic systems (including their functions) imply the destruction of systems and functions of a higher order; (ii) structural - according to which the systems of lower orders constitute or belong to the systems of higher order;

(iii) functional - according to which each function of higher order is realized by the structure or mechanisms of lower order. (INGARDEN [1972], pp. 139142). ${ }^{9}$

A given ontological background - as has already been said - is in agreement with a biological approach and does not distinguish a human being from other natural beings. But what is specific for man?

The essence is the specificity of a human being as a rational, active being which is able to make a choice in the light of accepted norms and values. Thus, relativeness in this system model is also essential in the interaction considered in the cultural-historical-social environment of the agent. But looking into the inner structure of the human being as a person, the constitutive factor for being a person is - in the language of phenomenology - its ontic centre which is the conscious "self", taken together with its "flow of experiences" (Germ. Erlebnises). In such an approach, the "self" is treated dynamically. According to Ingarden's conception, the root of the self, which is equipped by all its abilities, is the soul (psyche).Instead of Ingarden's "soul" I prefer to speak about the content of consciousness, first of all its propositional content, organized in the system of someone's knowledge together with his or her system of values and norms. In the flow of experiences someone's feelings, moods, thoughts, emotions are appeared, one can say everything that has been traditionally prescribed to psyche (in fact - all psychic life). As it is seen, the category of "self" is not treated as pure and absolute, but it is the centre of a concrete psychophysical individual (INGARDEN [1961] p. 542). Some commentators of Ingarden's writings mention three concepts of a subject (self): (1) as a realizer of acts of consciousness, (2) as a specific centre of human personality, (3) as something which conveys the whole human being in its psychophysical unity

\footnotetext{
${ }^{9}$ See also POCZOBUT [2010], pp. 95-96.
} 
(FIZER [1995], pp. 121-128). Speaking about the centre is not in the sense of the brain sciences, but in a certain sense of the ontology of the mind. This centre is just the essence of being a person who is able to undertake his or her action according to own choices, and to be responsible for them. Speaking in the language of Ingarden's epistemology, self by satisfying acts of consciousness is their realizers and bearers (cf. INGARDEN [1961], p. 191). As Poczobut stresses following Ingarden, in order to be a realizer as a subject of own acts the man must be partially independent from his environment - he must have his own relatively autonomous inner space (virtual space of his mind). But from the other side, he must admit causal-information interactions both inner (from the content of his consciousness, from his psychic life and from his bodily systems) and external (from his environment). (POCZOBUT [2010], pp. 93-94).

Ingarden's category of psyche (soul), like the body, is also treated as a relatively isolated system. Thus, they (i.e. soul and body) can interact with themselves. Taken into account what I have said about the soul, I repeat here that the agent's beliefs and thoughts influence his decisions to undertake his concrete actions (for instance, to visit his friend in hospital, to go to the theatre, to begin gymnastics). The body does not need to be especially manifested and the traditional dualistic frame is not adequate to give an explanation of human action because we are not dealing with any simple interactions between the psyche (here, mainly, the content of consciousness) and the body. Taking into account a human being as a compound multi-dimensional system consisting in different kinds of subsystems, connected in different ways and at different levels, we are dealing with a compound structure in the framework of which there are many different types of functions and processes studied by science. However, the basis of this structure is ontological.

Given such a "strong" philosophical perspective, how to reply to those naturalistically oriented philosophers and cognitive scientists who say that our consciousness is founded on brain processes and our choices are determined neuronally? I do not reject the scientific thesis that consciousness emerged from brain processes. But the content of consciousness (the content of mental states) requires access to the external world. In our mind we build our knowledge, we are able to make reflection, to utter judgments, to estimate our actions and so on. Thus, our choices are not only the result of neurophysiological determination. They are considered at a different level than the neurophysiological one, although they are not quite separated from it because they are physically realized in processes of thinking by undertaking our decisions. There can be cases in which human actions and decisions are not free, but determined neurophysiologically (as under the influence of special substances or in some cases of schizophrenia for instance). The presented approach within the framework of the Ingardenian conception of a system permits different degrees of determination of human actions which are extended in their varieties in 
individual and social life. In the system model, the human being, in the inner structure of its organism, needs to be isolated in order to be physiologically determined, but, according to the assumption given in this paper, it is only partially isolated in a special way which allows it to interact with its environment and gives room for free will.

\section{Conclusion}

As a philosopher, I looked for the ontological framework which would give a theoretical foundation for human action undertaken as the result of free and rational choice.

The following statements were theses or assumptions of my view.

1. Causal conditions are not sufficient to make choices in the sense "to make a decision".

It is so, because

2. Causality occurs at the physical level.

3. Decisions are at the epistemic level.

4. The mistaking of both levels comes to the error of justification (or the paradoxes of irrationality, as it has been described by Donald Davidson among others [1963]).

\section{But}

5. It $(2 \& 3)$ does not mean that there are no connections between domains of both levels (the same as among other levels important in studies of human actions).

6. The compound structure of the human being treated as a partially open and a partially isolated system (also in its inner structure as the set of subsystems) allows it to enter into compound (both intrinsic and external) interactions.

7. Taken into account, the inner complexity and integrity of the human being as a person open to the system of norms and values allows the thesis about the existence of free will to be defended.

It is so because

8. A person is able to undertake decisions in the light of accepted norms and values. 


\section{References}

AGUILAR, J., BUCKAREFF, A. [2010], (eds), Causing Human Action: New Perspectives on the Causal Theory of Acting, MIT Press, Cambridge Mass.

ALVAREZ, M. [2010], Kinds of Reasons: An Essay on the Philosophy of Action, Oxford University Press, Oxford.

ANSCOMBE, E. M. [(1963) 2000], Intentions, Harvard University Press, Cambridge Mass.

BERTALANFFY, L. von [1957], "An Outline of General Systems Theory”, [in:] British Journal For Philosophy Of Science, vol. I-II.

BREMER, J. [2013], Is Free Will Free? Compatibilism in the Context of Interdisciplinary Research, (in Polish), Publ. WAM, Kraków.

CZELAKOWSKI, J. [2015], Freedom and Enforcement in action. A Study in Formal Action Theory, Springer, Dordrecht.

DAVIDSON, D. [1963], “Actions, reason and causes”, Journal of Philosophy, vol. 60, pp. 685700, repr. [in:] D. Davidson, Essays on Actions and Events, Clarendon Press, Oxford 1980, pp. 3-21.

FINLAY, S. [2010], "What Ought Probably Means and Why You Can't Detach It", Synthese, vol. 177, pp. 67-89.

FIZER, J. [ 1995], "Deconstruction of subject in the light of Ingarden's Epistemology", (in Polish) [in:] In the Range of Roman Ingarden's Philosophy (in Polish), PWN, Warszawa-Kraków, pp. 121-128.

GILBERT, M. [2000], Sociality and Responsibility. New Essays in Plural Subject Theory, Rowman \& Littlefield, Lanham MD.

GOLDMAN, A. [1970], A Theory of Human Action, Prentice-Hall, Englewood Cliffs NJ.

GOŁASZEWSKA, M. [1975], "Ingardenian Conception of Person" (in Polish), Studia Filozoficzne, N. 7, pp. 125-141.

GRICE, H. P. [1971], "Intention and Certainly", Proceedings of the British Academy, vol. 57, pp. 263-279.

HILDEBRAND, v. D. [(1916)/1969], "Die Idee der sittlichen Handlung”, [in:] Die Idee von der sittlichen Handlung. Sittlichkeit und ethische Wererkenntnis, K. Mertens, (ed.), Wissenschaftliche Buchgeselschaft, Darmstadt, pp. 1-126.

INGARDEN, R. [1961], Controversy over the Existence of the World, vol. II (Polish edition), PWN, Warszawa.

INGARDEN, R. [1972], The Booklet about the Man, (in Polish), Wyd. Literackie, Kraków.

KOTARBIŃSKA, J. [(1934)/1990], "The Analysis of the Concept of Chance. The Contribution to the Philosophical Vocabulary", (in Polish), [in:] Problems from Theory of Science and Theory of Language (in Polish), PWN, Warszawa, pp. 59-76.

KOTARBIŃSKI, T. [1965], Praxeology. An Introduction to the Science Efficient Action, PWNPergamon, Warsaw-Oxford. 
LUBAŃSKI, M. [1997], "Information - System”, [in:] M. Heller, M. Lubański, Sz. Ślaga (eds), Philosophical Issues of Contemporary Science (in Polish), ATK, Warszawa, pp. 15-155.

ŁUKASIEWICZ, D. [2014], Providence, Freedom, Chance. The Studies from the Analytic Philosophy of Religion (in Polish), W Drodze, Poznań-Kraków.

PAPRZYCKA, K. [2012], "Analytical philosophy of action” (in Polish), [in:] M. Miłkowski, R. Poczobut (eds), The Guide to the Philosophy of Mind (in Polish), WAM, Kraków, pp. 465-494.

PIETROSKI, P. [2000], Causing Actions, Oxford University Press, New York.

POCZOBUT, R. [2010], "Consciousness as a Relatively Isolated System" (in Polish), Analiza i Egzystencja, vol. 11, pp. 81-102.

SCHELER, M. [1987], Person and Self-Value. Three Essays, M.S. Frings (ed. and partial transl.), Martinus Nijhoff, Dordrecht-Boston.

SCHELER, M. [1992], On Feeling, Knowledge and Valuing. Selected Writings, H. J. Beshady (ed. and transl.), The Chicago University Press, Chicago.

TRYPUZ, R. [2008], Formal Ontology of Action. A Unifying Approach, Catholic University of Lublin, Lublin.

VELlEMAN, J. D. [1989], Practical Reflection, Princeton University Press, Princeton.

WOJTYŁA, K. [1969/1979], Person and Act. The Undertaking of "Person”, transl. A. Potocki, Kluwer, Dordrecht.

WRIGHT, G. [1968], "An Essay in Deontic Logic and the General Theory of Action", Acta Philosophica Fennica 21.

ZHU, J., THAGARD, P. [2002], "Emotion and Action", Philosophical Psychology, vol. 19, N. 1, pp. 19-36.

ŻEGLEŃ, U. M. [1990], Modality in Logic and Philosophy. The Ontological Foundations, (in Polish), Warsaw University, Warszawa. 